\title{
Micelle-based Nanoreactors Containing Ru-porphyrin for the Epoxidation of Terminal Olefins in Water
}

\author{
Jie Lu, Linus Liang, and Marcus Weck* \\ Molecular Design Institute and Department of Chemistry, New York University, 100 \\ Washington Square East, New York, NY 10003, USA \\ marcus.weck@nyu.edu
}

\begin{abstract}
This contribution introduces a strategy to use $\mathrm{Ru}(\mathrm{II})$-porphyrin complexes as catalysts for the epoxidation of alkenes in water. The design is based on shell-crosslinked micellebased nanoreactors with hydrophobic cores and hydrophilic shells as supports for the $\mathrm{Ru}(\mathrm{II})$ porphyrin complexes. The supported complexes are efficient catalysts for oxidation reactions, specifically the selectively oxidation of alkenes to epoxides. The presented strategy is the first system that allows for running Ru-catalyzed epoxidation reactions in water.
\end{abstract}

\section{Introduction}

Catalytic oxidations of organic substrates play a key role in the pharmaceutical and fine chemical industry. In Nature, a well-known monooxygenase for aerobic oxidation is Cytochrome P-450, which features an iron porphyrin core. This motivated investigations into the use of synthetic metalloporphyrin-catalyzed oxidation systems. ${ }^{1,2}$ Ruthenium porphyrins, in particular, show high activity and stability ${ }^{3-6}$ and have been 
studied for the epoxidation of alkenes for about 35 years. ${ }^{7}$ First explored by Groves and co-workers, a ruthenium porphyrin-based oxidation system usually consists of terminal oxidants (e.g. iodosylbenzene, sodium hypochlorite, or 2,6-dichloropyridine-N-oxide) and a solvent such as chloroform or benzene. ${ }^{8,9}$ Traylor and co-workers proposed using $\mathrm{H}_{2} \mathrm{O}_{2}$ as an environmentally clean oxidant. ${ }^{10,11}$ This modification, however, only works with electron-deficient metalloporphyrins as ligands and solvent systems such as $\mathrm{CH}_{2} \mathrm{Cl}_{2} / \mathrm{CH}_{3} \mathrm{OH} / \mathrm{H}_{2} \mathrm{O}$ or $\mathrm{CH}_{3} \mathrm{CN} /$ alcohol. ${ }^{12}$ Protic solvents like alcohols function as a general-acid catalyst that facilitates O-O bond heterolysis, thus generating a high-valent oxometal porphyrin intermediate. ${ }^{13,14}$ While water would be the ideal green solvent, it cannot be used as a majority component in a $\mathrm{CH}_{3} \mathrm{CN} / \mathrm{H}_{2} \mathrm{O}$ mixture due to the insolubility of the alkene substrate and the Ru-porphyrin catalyst in water.

Our strategy to overcome the solubility problem is by supporting the catalyst on a polymeric micelle. Polymeric micelle-supported catalytic systems, in which the active catalyst is located in the hydrophobic micelle core, allow for efficient and selective catalysis in water due to the shielding effect of the hydrophilic micelle shell. ${ }^{15-26}$ In recent years, micelle-bound catalysts have garnered increased attention, as they feature properties such as local concentration effects, shielding, and substrate selectivity, often in conjunction with greater reusability over traditional homogeneous analogs. ${ }^{24}$ Additionally, the use of water as the solvent makes the reaction not only environmentally friendlier but can also improve the rate and selectivity of the desired transformation. ${ }^{27,28}$ We hypothesized that such a polymeric micelle-supported catalytic systems should be able to carry out the epoxidation of terminal olefins in aqueous environments. One drawback of micelle-bound catalysts is the stability of the self-assembled micelle 
structure which is dynamic in nature. Shell cross-linked micelles (SCMs) are able to overcome this disadvantage and provide a more robust polymeric assembly. ${ }^{29-33}$ This contribution reports SCM-supported Ru-porphyrin complexes as the first example for carrying out Ru-porphyrin catalyzed epoxidations in water.

\section{Results and Discussion}

Our crosslinked micelle support is formed from amphiphilic ABC-triblock copolymers based on poly(2-oxazoline)s (Scheme 1) containing a hydrophobic block (A) and a hydrophilic block (C). Crosslinking block (B) is introduced as the middle layer.
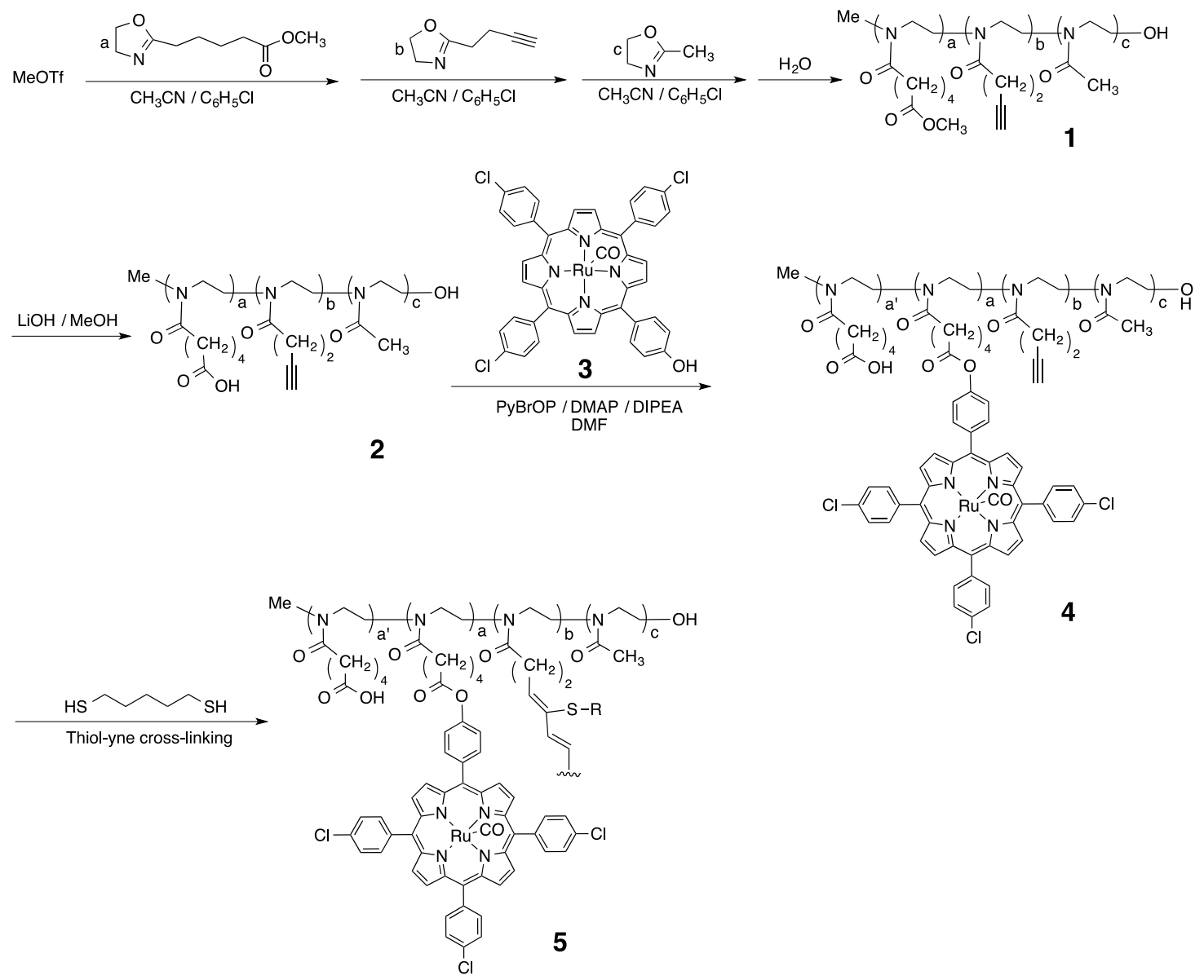

Scheme 1. Schematic representation for the synthesis of the micelle supported metal catalyst. 
The 2-substituted 2-oxazoline monomer A was synthesized following literature procedures. ${ }^{34}$ Monomer B was synthesized in a two-step one-pot reaction in $72 \%$ yield (see SI). ${ }^{35}$ Poly(2-oxazoline) triblock copolymers were synthesized via cationic ringopening polymerization using methyl triflate as the initiator. The polymerization process was monitored by ${ }^{1} \mathrm{H}$ NMR spectroscopy and gel-permeation chromatography (GPC) (see SI). The disappearance of the monomer peak in the ${ }^{1} \mathrm{H}$ NMR spectrum at $3.8 \mathrm{ppm}$ and 4.2 ppm and clear shifts of the GPC traces after each block formation indicated the stepwise growth of the block copolymer. The dispersity $(\nexists)$ and apparent molecular weight $\left(\mathrm{M}_{\mathrm{n}}{ }^{\mathrm{app}}\right)$ of the final triblock copolymer $\mathbf{1}$ are 1.23 and 7,700 $\mathrm{g} \mathrm{mol}^{-1}$ respectively, as determined by GPC using poly(styrene) standards.

The terminal ester groups of the hydrophobic block A were hydrolyzed and converted into carboxylic acids. They serve as functional handles to attach the hydroxylfunctionalized Ru-porphyrin complexes. The hydroxyl-functionalized unsymmetrical porphyrin ligand was synthesized following Lindsey's method and ruthenium metallation was carried out by refluxing the porphyrin ligand and $\mathrm{RuCl}_{3}$ in decalin to yield the target complex $3^{36,37}$ The Ru(II)-porphyrin containing amphiphilic block copolymer 4 was prepared by the esterification of polymer 2 and complex 3 . Micelle formation was induced by dissolving 4 in water at $5 \mathrm{mg} / \mathrm{mL}$. Dynamic light scattering (DLS) indicated the presence of micelle aggregates with $R_{h}{ }^{a p p}=47 \pm 4 \mathrm{~nm}$.

To form the SCM-supported Ru-porphyrin nanoreactor 5, the thiol-yne reaction was chosen for the crosslinking step between a dithiol linker and the carbon-carbon triple bonds in block $\mathrm{B}^{38}$ (Scheme 1). Using 2,2-dimethy-2-phenylacetophenone (DMPA) as the radical initiator, the thiol-yne reaction was completed via a 24 hour UV-irradiation of 
the micelle solution at $4{ }^{\circ} \mathrm{C}$. The successful cross-linking step was confirmed by the stable hydrodynamic radius of $\mathbf{5}$ in different solvents as analyzed by DLS (see SI). The size of nanoreactor 5 was further characterized via SEM to give a radius of $30 \pm 5 \mathrm{~nm}$ that is in agreement with the hydrodynamic radius of $32 \pm 6 \mathrm{~nm}$ obtained by DLS analysis.

Epoxidation of styrene with $\mathrm{H}_{2} \mathrm{O}_{2}$ as the oxygen source using terminal alkenes as substrates in an aqueous environment was investigated using an unsupported Ru(II)porphyrin complex as control experiment as well as nanoreactors $\mathbf{4}$ and $\mathbf{5}$. For the small molecule catalysts, different $\mathrm{CH}_{3} \mathrm{CN}$ and water solvent mixtures were tested. Poor conversions were observed when the water content was higher than 50\% (Table 1) most likely due to the insolubility of the $\mathrm{Ru}(\mathrm{II})$-porphyrin complex.

Table 1. Solvent system tests of unsupported Ru(II)-porphyrin complex catalyzed epoxidation of styrene.

\begin{tabular}{cccc}
\hline Entry & $\mathrm{CH}_{3} \mathrm{CN}: \mathrm{H}_{2} \mathrm{O}$ & Time (h) & Conv. (\%) \\
\hline 1 & $100: 0$ & 24 & 95 \\
2 & $80: 20$ & 24 & 92 \\
3 & $50: 50$ & 24 & 86 \\
4 & $40: 60$ & 24 & 20 \\
5 & $20: 80$ & 24 & 0 \\
\hline
\end{tabular}

Nanoreactors $\mathbf{4}$ and $\mathbf{5}$ both worked in aqueous environments for the epoxidation step, demonstrating $95 \%$ conversions over 24 hours, thus validating the hypothesis that polymeric micelles can be used as matrices to carry out epoxidations under aqueous 
conditions. Our working hypothesis is that hydrophobic molecules, such as styrene, can easily diffuse into the micellar core. Additionally, the presence of amide bonds and carboxylic acid groups in the hydrophobic block enables small amounts of water and $\mathrm{H}_{2} \mathrm{O}_{2}$ to diffuse into the core and serve as the general-acid to facilitate the $\mathrm{O}-\mathrm{O}$ bond heterolysis. $^{39}$ With all reagents and the $\mathrm{Ru}(\mathrm{II})$-porphryin in the confined space, the epoxidation proceeded similarly to an organic/water solvent mixture.

Kinetic experiments involving 4 and 5 were performed using ${ }^{1} \mathrm{H}$ NMR spectroscopic analysis to monitor the reaction progress and to determine conversions (Figure 1). The reaction rate and the final conversion from $\mathbf{5}$ were slightly lower than $\mathbf{4}$, likely owing to the permeability difference between $\mathbf{4}$ and $\mathbf{5}$. Due to the cross-linking layer in $\mathbf{5}$, the diffusion of a substrate might be slowed down thus lowering the rate. For the same reason, a product might diffuse out of $\mathbf{5}$ slower than $\mathbf{4}$, thus shifting the equilibrium of the reaction.

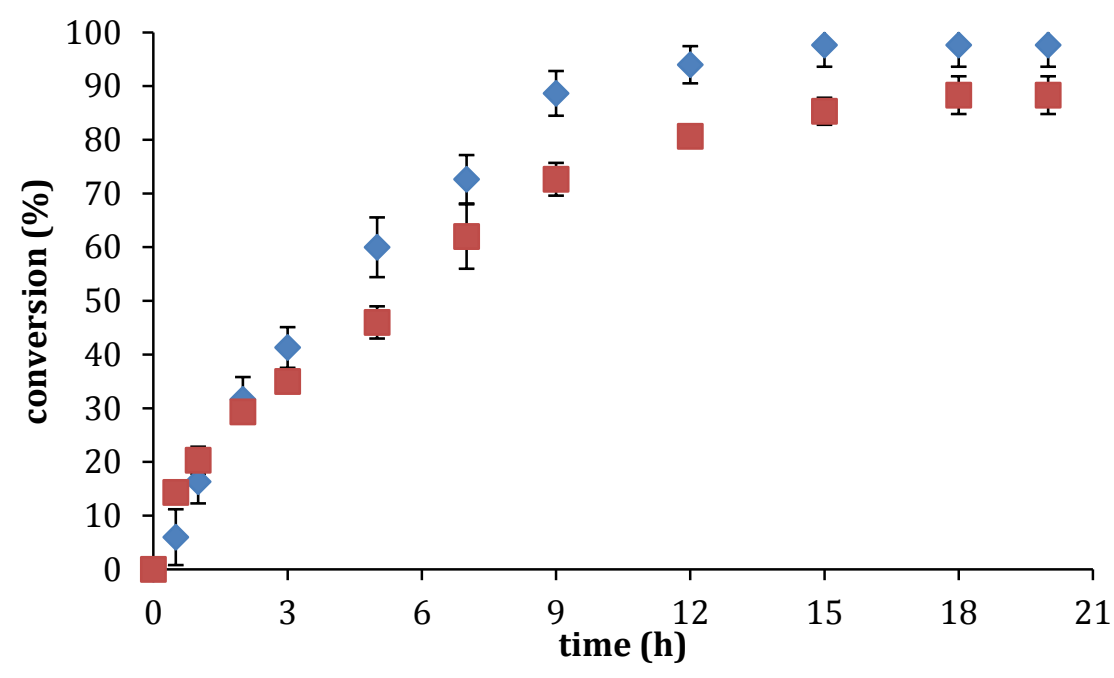

Figure 1. Kinetic evaluation of the epoxidation of styrene for the micelle supported $\mathrm{Ru}-$ porphyrin catalysts 4 (blue diamond) and 5 (red square). Conditions: $0.05 \mathrm{mmol}$ styrene, $0.075 \mathrm{mmol} \mathrm{H}_{2} \mathrm{O}_{2}, 0.35 \mathrm{~mol} \%$ catalyst loading in $1 \mathrm{~mL} \mathrm{D}_{2} \mathrm{O}$ at room temperature. 
Further tests using 4 revealed that a variety of alkenes can be used as substrates (Table 2). The reactions were conducted at room temperature in water for all substrates examined. Entries 1, 2, and 3 of Table 2 are styrene derivatives. The ortho-bromo group in substrate 2 slows down the epoxidation reactions (only 39\% conversion within 48 hours), likely due to a combination of electron withdrawal and steric hindrance near the reaction site. Entries 4 and 5 are alkyl alkene substrates. 1-Hexene was converted to 1,2epoxyhexane after 24 hours with $99 \%$ conversion. The cycloalkane vinylcyclohexane reached $94 \%$ conversions after 48 hours. A similar substrate-screen was carried out using 5 resulting in the same trends albeit with longer reaction times. Compared to the nonsupported small molecule catalyst, ${ }^{13,40}$ the micelle-supported catalyst systems only yield the target epoxide products with no over oxidized side-products, such as aldehydes or acids.

Table 2. Substrate scope for the epoxidation with nanoreactor $4^{[a]}$

\begin{tabular}{ccccc}
\hline entry & substrate & cat. loading $(\mathrm{mol} \%)$ & time $(\mathrm{h})$ & conv. $(\%)^{[\mathrm{b}]}$ \\
\hline 1 & styrene & 0.5 & 24 & 99 \\
2 & 2-bromostyrene & 1 & 48 & 39 \\
3 & 4-vinylbenzylchloride & 1 & 48 & 94 \\
4 & 1-hexene & 0.5 & 24 & 99 \\
5 & vinylcyclohexane & 1 & 48 & 94 \\
\hline
\end{tabular}

[a] Conditions: $0.05 \mathrm{mmol}$ substrate, $0.075 \mathrm{mmol} \mathrm{H}_{2} \mathrm{O}_{2}, 0.35 \mathrm{~mol} \%$ catalyst loading in 1 $\mathrm{mL} \mathrm{H}_{2} \mathrm{O}$ at room temperature. [b] Determined by $\mathrm{GC}$ analyses

Due to the cross-linking, nanoreactor $\mathbf{5}$ can be recovered from the reaction mixture by passing through a 10,000 cutoff ultrafiltration membrane. Recovered $\mathbf{5}$ can be 
re-used easily. For example, the epoxidation of styrene using recycled $\mathbf{5}$ yielded $95 \%$ conversions over 24 hours. Within three recycling tests, 5 maintained its high catalytic efficiency with yields of 96 or $95 \%$ in each step (Table 3).

Table 3. Recycling data of $\mathbf{5}$ for the epoxidation of styrene in water. ${ }^{[a]}$

\begin{tabular}{ccc}
\hline cycle & time $(\mathrm{h})$ & ${\text { conv. }(\%)^{[\mathrm{b}]}}$ \\
\hline 1 & 24 & 96 \\
2 & 24 & 95 \\
3 & 24 & 95
\end{tabular}

[a] Conditions: $0.5 \mathrm{mmol}$ styrene, $0.75 \mathrm{mmol} \mathrm{H}_{2} \mathrm{O}_{2}, 0.5 \mathrm{~mol} \%$ catalyst loading in $1 \mathrm{~mL}$ $\mathrm{H}_{2} \mathrm{O}$ at room temperature. [b] Determined by GC analyses

\section{Conclusion}

Synthetic amphiphilic block copolymers based on poly(2-oxazoline) with functional handles in the hydrophobic block were designed and synthesized to engineer micellebased nanoreactors with hydrophilic and hydrophobic compartments. Ru(II)-porphyrin complexes were attached to the micelle core that then can serve as catalytic site for the epoxidation of terminal alkenes. The epoxidation reaction proceeds in water. This micelle-supported catalyst strategy combines easy recycling, high efficiency and product selectivity in an environmentally friendly aqueous system.

\section{Acknowledgement}

Funding provided by the U.S. Department of Energy, Office of Basic Energy Sciences, through Catalysis Science Contract DE-FG02-03ER15459, is gratefully acknowledged. 


\section{References}

1 Sheldon, R. A. Metalloporphyrins in Catalytic Oxidations. Marcel Dekker, Inc. New York (1994).

2 Montanari, F. \& Casella, L. Metalloporphyrins Catalyzed Oxidations, Kluwer Academic Press, Dordrecht (1994).

3 Murahashi, S.-I. \& Komiya, N. in Biomimetic Oxidations Catalyzed by Transition Metal Complexes. ed. B. Meunier, Imperial College Press, London, 563 (2000).

4 Murahashi, S.-I. \& Komiya, N. in Ruthenium in Organic Synthesis. ed. S.-I. Murahashi, Wiley-WCH, Weinheim, 53 (2004).

5 Pagliaro, M., Campestrini, S., Ciriminna, R. Chem. Soc. Rev. 34, 837-845 (2005).

6 Murahashi, S.-I. \& Zhang, D. R. Chem. Soc. Rev. 37, 1490-1501 (2008).

7 Che, C.-M., Huang, J.-S. Chem. Commun. 2009 (2009).

8 Groves, J. T., Myers, R. S. J. Am. Chem. Soc. 105, 6 (1983).

9 Groves, J. T., Nemo, T. E., Myers, R. S. J. Am. Chem. Soc. 101 (1979).

10 Traylor, T. G., Fann, W. P., Bandyopadhyay, D. J. Am. Chem. Soc. 111, 80098010 (1989).

11 Traylor, T. G., Kim, C., Richards, J. L., Xu, F., Perrin, C. L. J. Am. Chem. Soc. 117, 3468-3474 (1995).

12 Traylor, T. G., Kim, C., Fann, W. P., Perrin, C. L. Tetrahedron 54, 7977-7986 (1995).

13 Nam, W., Oh, S.-Y., Sun, Y. J., Kim, J., Kim, W.-K., Woo, S. K., Shin, W. J. Org. Chem. 68, 7903-7906 (2003).

14 Nam, W., Lim, M. H., Lee, H. J., Kim, C. J. Am. Chem. Soc. 122, 6641-6647 (2000).

15 Nuyken, O., Persigehl, P., Weberskirch, R. Macromol. Symp. 177, 163-173 (2002).

16 Zarka, M. T., Nuyken, O., Weberskirch, R. Chem. Eur. J. 9, 3228-3234 (2003).

17 Nuyken, O., Weberskirch, R., Bortenschlager, M., Schonfelder, D. Macromol. Symp. 215, 215-229 (2004).

18 Helms, B., Guillaudeu, S. J., Xie, Y., McMurdo, M., Hawker, C. J., Fréchet, J. M. J. Angew. Chem. Int. Ed. 44, 6384-6387 (2005). 
19 Rossbach, B. M., Leopold, K., Weberskirch, R. Angew. Chem. Int. Ed. 45, 13091312 (2006).

20 Chi, Y. G., Scroggins, S. T., Fréchet, J. M. J. J. Am. Chem. Soc. 130, 6322-6323, (2008).

21 Liu, Y., Pinon, V., Weck, M. Polym. Chem. 2, 1964-1975 (2011).

22 Liu, Y. Wang, Y., Lu, J., Pinon III, V., Weck, M. J. Am. Chem. Soc. 133, 1426014263 (2011).

23 Cotanda, P., Lu, A., Patterson, J. P., Petzetakis, N., O'Reilly, R. K. Macromolecules 45, 2377-2384, (2012).

24 Cotanda, P., Petzetakis, N. \& O'Reilly, R. K. MRS Commun. 2, 119-126 (2012).

25 Lu, A., O'Reilly, R. K. Curr. Opin. Biotechnol. 24, 639-645 (2013).

26 Lu, J., Dimroth, J., Weck, M. J. Am. Chem. Soc. 137, 12984-12989 (2015).

27 Dwars, T., Paetzold, E., Oehme, G. Angew. Chem. Int. Ed. 44, 7174-7199 (2005).

28 Li, J., Tang, Y., Wang, Q., Li, X., Cun, L., Zhang, X., Zhu, J., Li, L., Deng, J. J. Am. Chem. Soc. 134, 18522-18525 (2012).

29 Elsabahy, M., Wooley, K. L. Chem. Soc. Rev. 41, 2545-2561 (2012).

30 Elsabahy, M., Wooley, K. L. J. Polym. Sci. Polym. Chem. 50, 1869-1880 (2012).

31 O'Reilly, R. K., Joralemon, M. J., Hawker, C. J., Wooley, K. L. J. Polym. Sci. Polym. Chem. 44, 5203-5217 (2006).

32 O'Reilly, R. K., Joralemon, M. J., Wooley, K. L., Hawker, C. J. Chem. Mater. 17, 5976-5988 (2005).

33 Joralemon, M. J., O'Reilly, R. K., Hawker, C. J., Wooley, K. L. J. Am. Chem. Soc. 127, 16892-16899 (2005).

34 Zarka, M. T., Nuyken, O., Weberskirch, R. Chem. Eur. J. 9 (2003).

35 Puts, R. D., Sogah, D. Y. Tetrahedron Lett. 35, 5779-5782 (1994).

36 Lindsey, J. S., Schreiman, I. C., Hsu, H. C., Kearney, P. C., Marguerettaz, A. M. J. Org. Chem. 52, 827-836 (1986).

37 Yu, X.-Q., Huang, J.-S., Yu, W.-Y., Che, C.-M. J. Am. Chem. Soc. 122, 53375342 (2000).

38 ten Brummelhuis, N., Schlaad, H. Polym. Chem. 2, 1180-1184 (2011).

39 Panicucci, R., Bruice, T. C. J. Am. Chem. Soc. 112, 6063-6071 (1990). 
40 Vaz, A. D. N., McGinnity, D. F., Coon, M. J. Proc. Natl. Acad. Sci. USA 95, 3555-3560 (1998). 


\section{Graphical Abstract}

\section{Micelle-based Nanoreactors Containing Ru-porphyrin for the Epoxidation of Terminal Olefins in Water}

Jie Lu, Linus Liang, and Marcus Weck*

Molecular Design Institute and Department of Chemistry, New York University, 100

Washington Square East, New York, NY 10003, USA

marcus.weck@nyu.edu

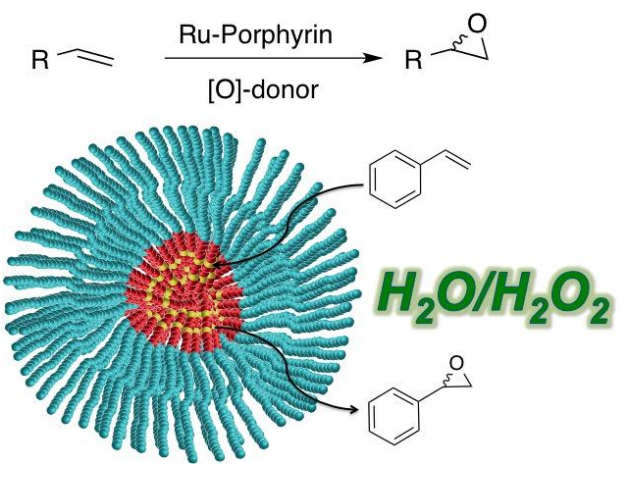

